\title{
Breast cancer and pregnancy: diagnosis and treatment options
}

\author{
E. A. te Velde, G. Sonke, E. J. Th. Rutgers \\ The Netherlands Cancer Institute/Antoni van Leeuwenhoek Hospital, Amsterdam, The Netherlands.
}

\section{Case report}

A 36-year-old woman had noticed a lump in her right breast, just after she had discovered she had been pregnant for about 6 weeks. At referral to our clinic, on physical examination a palpable mass was found in the upper quadrant of her right breast, sized $2 \mathrm{~cm}$ in diameter.

Diagnostic mammography and ultrasound were performed elsewhere and showed an uncertain density on mammography and an uncertain hypoechoic structure on ultrasound cranial to the righter mammilla, sized $15 \mathrm{~mm}$ in diameter. Utrasound of the axilla showed no suspected lymph nodes. A core biopsy proved an adenocarcinoma.

After discussing the different options, the patient preferred a skin-sparing mastectomy with nipple banking and sentinel node biopsy. The sentinel node was retrieved by $85 \mathrm{MBq}$ technetium-99m nanocolloid intra-tumoural injection, without using blue dye.

At histopathology the tumour was T1 $(15 \mathrm{~mm})$ in size, B\&R grade II; the sentinel node was tumournegative after multiple slicing and $\mathrm{IHC}$ staining with Cam 5.2; oestrogen receptor was $100 \%$ positive and progestin receptor was $100 \%$ positive; HER2neu was negative. The margins were free. The Mammaprint ${ }^{\mathrm{R}}$ showed a low-risk signature, that is no distant metastases within at least 5 years.

Since the patient was in her first trimester of pregnancy, and the child was very much desired,

Correspondence to: E. J. Th. Rutgers, The Netherlands Cancer Institute/ Antoni van Leeuwenhoek Hospital, Amsterdam, The Netherlands. E-mail: e.rutgers@nki.nl

Received: $15 / 10 / 08$

Accepted: 16/01/09

First published online 14/07/09

BCO/844/2008/CS finally, the patient opted for endocrine therapy. She will receive tamoxifen and ovarian suppression by LHRH agonist after her child delivery. She decided not to have adjuvant chemotherapy, particularly considering the high hormone responsiveness of the tumour and the Mammaprint low risk. In addition, due to her young age, she was referred to the genetic counselling department.

\section{Discussion}

Breast cancer is the second most common cancer in pregnant women. The prognosis of breast cancer is independent of the pregnancy, and termination of the pregnancy is not indicated [1]. Surgery is not contraindicated during the first trimester, but could be associated with low birth weight or premature labour [2].

Skin-sparing mastectomy was chosen over breast-conserving surgery in this patient to prevent radiotherapy during her pregnancy, as well as considering the higher local relapse rates after breast-conserving treatment in young women $[3,4]$. In younger women, 10-years risk of recurrence of $20 \%$ can be reduced to $10 \%$ by radiotherapy boost [5]. However, older radiation courses showed to be dangerous to the foetus [6], and although no data exist on effects of modern radiotherapy, it is not advised in the first trimester until after delivery (Dutch guidelines: http://www.oncoline.nl).

The sentinel node biopsy was performed using a lower dose of nanocolloid than usual. In a recent review, the axillary lymph node dissection is advocated as opposed to sentinel lymph node biopsy [7]. However, according to others, we believe that it can be performed safely [8,9], since - even with normal intra-tumoural dosage - the dose to the foetus is proven to be negligible [9]. We used a dose 
as low as reasonably achievable, since it has been shown that lower dosage can also provide accurate visualization of the sentinel node [10]. We did not use blue dyes because of the possibility of allergic reactions that may seriously affect the foetus [11].

In general, adjuvant chemotherapy can be administered during pregnancy, and if needed, preferably in the second and third trimester [12]. Endocrine or antibody treatment should be postponed until after delivery, especially because tamoxifen is found to be teratogenic or may lead to malformations of the foetus [13].

Based on traditional risk factors, our patient's 10 -years recurrence rate is $25 \%$, lowered by adjuvant hormonal treatment to $16 \%$. If combined with chemotherapy, her risk for recurrence would be $8 \%$, according to Adjuvant! Online. The Mammaprint 70 -genes profile is an independent prognostic factor in node-negative breast cancer and in this patient predicts a 10-years life expectancy of 88-97\% [14]. Leaving a 10-year relapse-free survival of $94-99 \%$ after adequate endocrine treatments.

Taking into consideration her tumour characteristics, combined with her low genomic risk as well as her pregnancy, she decided not to be treated with adjuvant chemotherapy.

\section{References}

1. Petrek JA, Moore A. Breast cancer treatment in pregnant or postpartum women and subsequent pregnancy in breast cancer survivors In: Harris JR, Lippman ME, Morrow M, Osborne CK (Eds.). Diseases of the Breast, 3rd edition. Philadelphia, USA: Lippincott Williams and Wilkins, 2004: 691-701.

2. Mazze RI, Kallen B. Reproductive outcome after anaesthesia and operation during pregnancy: a registry study of 5405 cases. Am J Obstet Gynecol 1989; 161: 1178-1185.

3. Bollet MA, Sigal-Zafrani B, Mazeau V, et al. Age remains the first prognostic factor for loco-regional breast cancer recurrence in young ( $<40$ years) women treated with breast conserving surgery first. Radiother Oncol 2007; 82(3): 272-280.

4. Kreike $B$, Hart AA, van de Velde $T$, et al. Continuing risk of ipsilateral breast relapse after breast-conserving therapy at long-term follow-up. Int $\mathrm{J}$ Radiat Oncol Biol Phys 2008; 71(4): 1014-1021.

5. Vrieling C, Collette L, Fourquet A, et al. EORTC Radiotherapy, Breast Cancer Groups. Can patient-, treatmentand pathology-related characteristics explain the high local recurrence rate following breast-conserving therapy in young patients? Eur J Cancer 2003; 39(7): 932-944.

6. Antypas C, Sandilos P, Kouvaris J. Fetal dose evaluation during breast cancer radiotherapy. Int $J$ Radiat Oncol Biol Phys 1998; 40: 995-999.

7. Navrozoglou I, Vrekoussis T, Kontostolis E, et al. Breast cancer during pregnancy: a mini-review. Eur $J$ Surg Oncol 2008; 34: 837-843.

8. Gentilini O, Masullo M, Rotmensz N, et al. Breast cancer diagnosed during pregnancy and lactation: biological features and treatment options. Eur J Surg Oncol 2005; 31(3): 232-236.

9. Pandit-Taskar N, Dauer LT, Montgomery L, St Germain J, Zanzonico PB, Divgi CR. Organ and fetal absorbed dose estimates from 99mTc-sulfur colloid lymphoscintigraphy and sentinel node localization in breast cancer patients. J Nucl Med 2006; 47(7): 1202-1208.

10. Valdés-Olmos RA, Jansen L, Hoefnagel CA, et al. Evaluation of mammary lymphoscintigraphy by a single intratumoral injection for sentinel node identification. J Nucl Med 2000; 41(9): 1500-1506.

11. Scherer K, Studer W, Figueiredo V, Bircher AJ. Anaphylaxis to isosulfan blue and cross-reactivity to patent blue $\mathrm{V}$ : case report and review of the nomenclature of vital blue dyes. Ann Allergy Asthma Immunol 2006; 96(3): 497-500.

12. Lenhard MS, Bauerfeind I, Untch M. Breast cancer and pregnancy: challenges of chemotherapy. Crit Rev Oncol Hematol 2008; 67(3): 196-203.

13. Barthelmes L, Gateley CA. Tamoxifen and pregnancy. Breast 2004; 13: 446-451.

14. Bueno-de-Mesquita JM, Linn SC, Keijzer R, et al. Validation of 70-gene signature in node-negative breast cancer. Breast cancer Res Treat 2008 (in press). 